\title{
The Protective Effect of Omega-3 Against Thioacetamide Induced Lipid and Renal Dysfunction in Male Rats
}

\author{
Davood Moghadamnia, ${ }^{1,2,}{ }^{*}$ Mokhtar Mokhtari, ${ }^{3}$ and Saeed Khatamsaz ${ }^{3}$ \\ ${ }^{1}$ Department of Biology, Fars Science and Research Branch, Islamic Azad University, Fars, IR Iran \\ ${ }^{2}$ Department of Biology, Shiraz Branch, Islamic Azad University, Shiraz, IR Iran \\ ${ }^{3}$ Department of Biology, Kazerun Branch, Islamic Azad University, Kazerun, IR Iran \\ "Corresponding author: Davood Moghadamnia, Department of Biology, Fars Science and Research Branch, Islamic Azad University, Shiraz, IR Iran. Tel: +98-9173874503, E-mail: \\ moghadamnia412@gmail.com
}

Received 2015 November 22; Revised 2016 February 16; Accepted 2016 October 28.

\begin{abstract}
Background: Thioacetamide causes lipid and kidney dysfunction.Omega-3 unsaturated fatty acids prevent the progression of renal diseases.

Objectives: This study aimed to assess the protective effects of omega-3 fish oil supplement on thioacetamide induced lipid and kidney dysfunction in male rats.

Methods: In this experimental study, 42 male rats were divided into 6 groups of 7: control group sham group which received 0.4 $\mathrm{mL}$ olive oil as a solvent, Thioacetamide group receiving thioacetamide at a dose of $150 \mathrm{mg} / \mathrm{kg}$ once as intraperitoneal injection, Experimental groups of 1,2 and 3 which received omega-3 fish oil supplement at the doses of $100,200,300 \mathrm{mg} / \mathrm{kg}$ orally for $3 \mathrm{months}$ respectively and then they received thioacetamide at the dose of $150 \mathrm{mg} / \mathrm{kg}$ intraperitoneally for once. The levels of serum creatinine, BUN, total cholesterol, LDL, HDL, FBS, triglyceride, sodium and potassium were measured. The pathological changes of tissue samples of the kidneys were studied after hematoxylin-eosin staining. The data were analyzed by SPSS-18 software and using one way ANOVA and Tukey as post hoc test. Significant level was considered to be $\mathrm{P}<0.05$.

Results: The mean serum levels of potassium in the second experimental group significantly decreased (5.26 \pm 0.02$)$ compared to the group receiving thioacetamide $(6.50 \pm 0)$. The mean serum sodium in all experimental groups decreased significantly compared to the group receiving thioacetamide. The mean serum levels of total cholesterol in experimental group 3 (66.80 \pm 1.46 ) significantly decreased compared to the group receiving thioacetamide ( $84 \pm 0.57)$. No significant changes were observed in the mean serum levels of FBS, BUN, HDL, LDL, triglycerides and creatinine in all experimental groups compared to the group receiving thioacetamide. All the experimental groups improved renal histological changes induced by thioacetamide and these protective effects were dose-dependent $(\mathrm{P} \leq 0.05)$.

Conclusions: The results of this study showed the protective effect of omega-3 fish oil supplement against thioacetamide induced lipid and renal dysfunction in male rats.
\end{abstract}

Keywords: Omega-3, Thioacetamide, Lipid and Renal Dysfunction, Rats

\section{Background}

Kidneys are vulnerable to damages caused by reactive oxygen species (ROS) [1]. Kidney damage can happen by an increase in the volume of blood flow to the kidneys and the filtration of a large amounts of toxins (which can be condensed in renal lobules). The kidneys respond to the increased toxins by creating multiple morphological changes which are together with interstitial or tubular changes and nephropathy [2].

Unsaturated fatty acids are named after the location of the double bond of the final carbon- methyl called omega carbon. Eicosapentaenoic acid (EPA) and docosahexaenoic acid (DHA) are among the Omega -3 fatty acids. Humans cannot synthesize these acids and they have to be obtained from food .The main sources of omega-3 are planktons and marine fishes [3]. In the study done by Ashtiyani et al. in 2012 it was shown that the oral adminstration of omega3 could alleviate tissue damage, oxidative stress and the reperfusion induced kidney dysfunction [4]. Aukema et al. in 2013 identified that fish oil diet can improve renal glomerular damage [5]. Omega-3 polyunsaturated fatty acids prevented an excessive malondialdehyde production in LPS-treated animals and stabilized renal Na, K-ATPase [6]. Omega 3 fatty acids can activate PPAR alpha (Peroxisome proliferator-activated receptor alpha) whereby the expression of oxidative fatty acids increases, resulting in a reduction in plasma and hepatic triglycerides [7]. 
Lipid and renal toxicities are associated with the toxic effects of drugs. High doses of these drugs can cause kidney failure and lipid mal-performance. Thioacetamide is an organic compound with the formula of $\mathrm{CH}_{3} \mathrm{CSNH}_{2}$. Thioacetamide is generally used as fungicidal and is a strong liver poison [8]. Thioacetamide is a strong nephrotoxic substrate [2]. By oxidase system function, thioacetamide is metabolized to its toxic metabolites sulfine (sulfoxide) and sulfene (sulfone) which are then spread in several organs, including plasma, liver, kidney, bone marrow, adrenal and other tissues $[9,10]$.

\section{Objectives}

Kidney and cardiovascular diseases are the major cause of morbidity and mortality. There is evidence that omega3 fatty acids could have a role in improving kidney and cardiovascular diseases. Due to the high incidence of kidney and cardiovascular diseases and the numerous side effects of chemical drugs, it is needed to look for safer drugs with lower side effects and higher effectiveness. In the present study, with respect to the low side effects of omega-3 polyunsaturated fatty acids, the protective effects of omega-3 fish oil supplement against lipid and renal dysfunction in thioacetamide induced male rats were investigated.

\section{Methods}

\subsection{Animal Experiments}

This was an experimental study. Animals were collected from Fars Razi vaccine and serum research institute. All guidelines for ethical conduct in the care and use of laboratory animals developed by the Ministry of Health and Medical Education were observed in the present study 42 male Wistar rats weighing $200 \pm 10$ grams and age range from 2.5 to 3 months were randomly divided into 6 groups of 7 and were kept in standard cages under identical conditions at a temperature of 22 to $20^{\circ} \mathrm{C}$ and a photoperiod of 12 hours of daylight and 12 hours of darkness. They had free access to food and water except at the time of testing and they were tested only once.

\subsection{Experimental Design}

Test animals were divided into 6 groups of 7 as follows: The control group which experienced no stress including no oral administration. Sham group which received $0.4 \mathrm{~mL}$ olive oil as a solvent of omega-3 fish oil supplement daily and orally for 3 months; Thioacetamide group: animals in this group received thioacetamide at a dose of $150 \mathrm{mg} / \mathrm{kg}$ intraperitoneally once at the end of the 3 months; The experimental group 1: animals in this group received $100 \mathrm{mg} / \mathrm{kg}$ of omega-3 fish oil supplement daily orally for 3 months and a single intraperitoneal injection of thioacetamide at a dose of $150 \mathrm{mg} / \mathrm{kg}$ at the end of 3 months; The experimental group 2: animals in this group received $200 \mathrm{mg} / \mathrm{kg}$ of omega-3 fish oil supplement daily orally for 3 months and a single intraperitoneal injection of thioacetamide at a dose of $150 \mathrm{mg} / \mathrm{kg}$ at the end of 3 months; The experimental group 3: animals in this group daily received $300 \mathrm{mg} / \mathrm{kg}$ of omega-3 fish oil supplement orally for 3 months and a single intraperitoneal injection of thioacetamide at a dose of $150 \mathrm{mg} / \mathrm{kg}$ at the end of the 3 months period. The doses of thioacetamide (StigmaAldrich, Switzerland) were selected according to previous studies $[11,12]$.

\subsection{Biochemical Study}

As the toxic effects of thioacetamide usually becomes apparent about 2 days after the injection, $48 \mathrm{~h}$ after the last injection all animals were anesthetized with ether (Merck, Germany), and their blood samples were directly taken from the hearts.

The obtained blood samples were kept under laboratory conditions for 20 minutes and then were centrifuged at 5000 rounds per minute for 15 minutes (Hettich, Germany).

\subsubsection{Determination of Creatinine}

After the serum was isolated, creatinine was measured by colorimetric method (by the kit from Darman Kav, Iran). In this method creatinine reacted with bicarbonate ion which produced a red-orange color. The greater the amount of creatinine, the more intense the color [13].

\subsubsection{Determination of BUN}

Blood urea nitrogen was measured by enzymatic hydrolysis. In this method, urea was hydrolyzed by urease ammonium enzyme and ammonium ion was created which could be measured by spectrophotometry. In Berthelot reaction, ammonia reacted with hypochlorite, phenol, acatalyst, and alkali to produce a stable blue complex (indophenol) [14].

\subsubsection{Determination of Glucose}

The blood glucose was measured by glucose oxidase method (aromatic test method). The oxygen released from glucose in the presence of glucose oxidase changed to 4 Aminoantipyrine and phenol in the presence of peroxidase formed kinonimin. The level of kinonimin was evaluated by photometry which measured the amount of glucose directly [15]. 


\subsubsection{Determination of Cholesterol and Triglyceride}

The total cholesterol was measured by enzymatic method (by the kit from Darman Kav, Iran).In this method the oxygen freed from cholesterol reacted with 4-Aminoantipyrine in the presence of oxidized cholesterol and created kinonimin which could be measured by photometry which determined the amount of cholesterol. LDL cholesterol was calculated using the Friedwald Equation:

$$
L D L-C=(\text { Total }-C)-\left(H D L-C+\frac{T G}{5}\right)
$$

HDL cholesterol was measured by colorimetric method (by the kit from Darman Kav, Iran). In this method phosphotungstic acid with lipoprotein created sedimentation in the presence of magnesium.

Serum triglyceride levels were measured by enzymatic method (by the kit from Darman Kav, Iran).In this method, first glycerol was isolated from fatty acids by lipase enzyme. After some steps, the oxygen released from glycerol with 4-Aminoantipyrine and phenol in the presence of peroxidase enzyme formed quinoneimine whose level was measured by photometry which was directly correlated with triglyceride [16].

\subsubsection{Determination of Sodium and Potassium}

Sodium and potassium were measured by Flame Photometer (Jenway, England) [17].

\subsection{Histological Tests}

The kidneys were removed after necropsy. The tissues were stabilized in formalin buffer $10 \%$. The dehydration was done by alcohol with different concentrations (from low to high). For clearing, the tissues were placed in two Xylene containers. Then in the infiltration stage, the tissues were soaked in melted paraffin $\left(65^{\circ} \mathrm{C}\right)$, each for an hour. In the molding stage leukhardt parts were used .All tissue slides were cut at 4 - 5 micron and hematoxylin-eosin was used to stain the tissues .All histological evaluations were done under the supervision of an experienced pathologist [18].

\subsection{Statistical Analysis}

SPSS software (Version18, Chicago, IL, USA) was used for data analysis. The ANOVA test was performed on the data. Tukey test was used to evaluate the significant differences of the data (Tukey-HSD) and all the differences were considered as significant at. The values of serum creatinine, blood urea nitrogen, total cholesterol, LDL cholesterol, HDL cholesterol, triglycerides, glucose, sodium and potassium were presented at.

\section{Results}

The serum concentrations of BUN, sodium, potassium, creatinine, total cholesterol, HDL and LDL cholesterol, and triglyceride in experimental, control, sham and thioacetamide groups were compared and statistical analysis was performed. Results were presented in tables. Tukey test was done to check the statistical analysis and values at $\mathrm{P} \leq 0.05$ were considered as significant.

The average concentration of serum BUN in the group receiving thioacetamide showed a significant decrease compared with the control group. The average concentration of serum BUN in all experimental groups receiving omega-3 fish oil supplement and thioacetamide significantly reduced in comparison to the control and sham groups. Moreover, the average concentration of serum BUN in all experimental groups receiving omega-3 fish oil supplement and thioacetamide increased compared to the group receiving thioacetamide, but it was not significant (Table 1). The average concentration of potassium in the group receiving thioacetamide significantly increased compared with the control and sham groups. The average serum potassium concentration only in the experimental group receiving $300 \mathrm{mg} / \mathrm{kg}$ omega-3 fish oil supplement and thioacetamide increased significantly compared to the control and sham groups. Furthermore, the mean serum potassium concentration only in the experimental group receiving $200 \mathrm{mg} / \mathrm{kg}$ omega-3 fish oil supplement and thioacetamide showed a significant decrease compared to the group receiving thioacetamide (Table 1 ). The mean serum sodium concentration in all experimental groups receiving omega-3 fish oil supplement and thioacetamide compared to the control and sham group significantly decreased. Also, the average serum sodium concentration in all experimental groups receiving omega-3 fish oil supplement and thioacetamide significantly decreased compared to the group receiving thioacetamide (Table 1). Comparing the mean serum creatinine levels between experimental, control, sham, thioacetamide groups did not show significant changes (Table 1 ).

The average concentration of serum FBS in the group receiving thioacetamide compared with the control and sham groups showed a significant decrease. The mean FBS concentration in all experimental groups receiving omega-3 fish oil supplement and thioacetamide showed no significant changes in comparison to the control group and the sham group. In addition, the average concentration of serum FBS in all experimental groups receiving omega-3 fish oil supplement and thioacetamide increased compared to the thioacetamide group, but the change was not significant (Table 2 ).

The average concentration of serum total cholesterol 
Table 1. The Effects of Different Doses of Omega-3 Fish Oil Supplement on Renal Dysfunction Induced by Thioacetamide in Male Rats

\begin{tabular}{|c|c|c|c|c|}
\hline Groups & BUN, mg/dL & $\mathbf{C r}, \mathbf{m g} / \mathbf{d L}$ & $\mathbf{K}, \mathbf{m e q} / \mathbf{L}$ & $\mathrm{Na}, \mathrm{meq} / \mathrm{L}$ \\
\hline Control & $28.60 \pm 1.07^{\mathrm{a}}$ & $0.76 \pm 0.02$ & $5.58 \pm 0.02^{\mathrm{a}}$ & $193.2 \pm 1.18$ \\
\hline Sham & $24.33 \pm 0.55$ & $0.77 \pm 0.02$ & $5.75 \pm 0.01^{\mathrm{a}}$ & $192.3 \pm 2.03$ \\
\hline Thioacetamide & $19.66 \pm 0.88$ & $0.75 \pm 0.03$ & $6.50 \pm 0$ & $197.2 \pm 0.58$ \\
\hline $100 \mathrm{mg} / \mathrm{kg}$ omega-3 fish oil supplement and thioacetamide & $23.50 \pm 0.85^{\mathrm{b}}$ & $0.72 \pm 0.02$ & $5.83 \pm 0.04$ & $166.5 \pm 1.52^{\mathrm{b}, \mathrm{c}}$ \\
\hline $300 \mathrm{mg} / \mathrm{kg}$ omega-3 fish oil supplement and thioacetamide & $20.75 \pm 0.94^{\mathrm{b}}$ & $0.66 \pm 0.04$ & $7.26 \pm 0.08^{b}$ & $180.2 \pm 1.59^{\mathrm{b}, \mathrm{c}}$ \\
\hline
\end{tabular}

Abbreviations: BUN, blood urea Nitrogen; Cr, Creatinine; K, Potassium; Na, Sodium.

${ }^{a}$ A significant difference between thioacetamide group and control and sham groups at $\mathrm{P}<0.05$.

${ }^{\mathrm{b}} \mathrm{A}$ significant difference between the control and sham groups and the experimental groups (omega-3 fish oil supplement and thioacetamide) at $\mathrm{P}<0.05$.

${ }^{\mathrm{C}}$ A significant difference between thioacetamide group with experimental groups (omega-3 fish oil supplement and thioacetamide) at $\mathrm{P}<0.05$.

Table 2. The Effects of Different Doses of Omega-3 Fish Oil Supplement on Thioacetamide Induced Lipid Dysfunction in Rats

\begin{tabular}{|c|c|c|c|c|c|}
\hline Groups & Total Cholesterol, mg/dL & HDL Cholesterol, mg/dL & LDL Cholesterol, mg/dL & $\mathrm{TG}, \mathrm{mg} / \mathrm{dL}$ & FBS, mg/dL \\
\hline Control & $52.75 \pm 3.32^{\mathrm{a}}$ & $20.50 \pm 1.04$ & $24.50 \pm 0.98$ & $49 \pm 3.47$ & $177.5 \pm 8.19^{\mathrm{a}}$ \\
\hline Sham & $56.25 \pm 3.77^{\mathrm{a}}$ & $21.60 \pm 1.07$ & $27.66 \pm 0.55$ & $50 \pm 3.86$ & $166 \pm 6.57$ \\
\hline Thioacetamide & $84 \pm 0.57$ & $20 \pm 0.57$ & $28.80 \pm 0.92$ & $75 \pm 6.80$ & $126 \pm 1.00$ \\
\hline $\begin{array}{l}100 \mathrm{mg} / \mathrm{kg} \text { omega-3 fish oil supplement } \\
\text { and thioacetamide }\end{array}$ & $70.66 \pm 0.55^{\mathrm{b}}$ & $21.83 \pm 0.90$ & $27.50 \pm 0.79$ & $59.67 \pm 3.76$ & $146.8 \pm 6.23$ \\
\hline $\begin{array}{l}200 \mathrm{mg} / \mathrm{kg} \text { omega-3 fish oil supplement } \\
\text { and thioacetamide }\end{array}$ & $71 \pm 1.22^{\mathrm{b}}$ & $21.80 \pm 0.58$ & $26 \pm 0.71$ & $59.50 \pm 2.50$ & $153.6 \pm 7.94$ \\
\hline $\begin{array}{l}300 \mathrm{mg} / \mathrm{kg} \text { omega-3 fish oil supplement } \\
\text { and thioacetamide }\end{array}$ & $66.80 \pm 1.46^{c}$ & $20.80 \pm 0.58$ & $26.80 \pm 0.58$ & $49.75 \pm 4.11$ & $143.6 \pm 3.62$ \\
\hline
\end{tabular}

Abbreviations: FBS, fasting blood sugar; HDL, high-density lipoprotein; LDL, low-density lipoprotein; TG, triglyceride.

${ }^{\mathrm{a}} \mathrm{A}$ significant difference between thioacetamide group and control and sham groups at $\mathrm{P}<0.05$.

${ }^{\mathrm{b}} \mathrm{A}$ significant difference between the control and sham groups and the experimental groups (omega-3 fish oil supplement and thioacetamide) at $\mathrm{P}<0.05$.

${ }^{\mathrm{c}}$ A significant difference between thioacetamide group with experimental groups (omega-3 fish oil supplement and thioacetamide) at $\mathrm{P}<0.05$.

in the group receiving thioacetamide significantly increased compared to the control and sham groups. The average concentration of serum total cholesterol in the experimental groups receiving 100, $200 \mathrm{mg} / \mathrm{kg}$ omega-3 fish oil supplement and thioacetamide showed significant increases compared to the control and sham groups. In addition, the average concentration of serum total cholesterol only in the experimental group receiving $300 \mathrm{mg} / \mathrm{kg}$ omega-3 fish oil supplement and thioacetamide showed significant decrease compared to the thioacetamide group (Table 2). No significant changes were detected in the average serum of HDL cholesterol, LDL cholesterol and triglyceride between experimental, control, sham, and thioacetamide groups (Table 2 ).

\subsection{Histological Findings}

Control and sham groups had normal glomerulus with a healthy normal Bowman's capsule (Figure 1A and 1B). The histological results of different kidney parts of the rats treated with thioacetamide showed renal morphological damage and necrosis of tubular epithelial cells (Figure 1C). In the group receiving thioacetamide, the Bowman capsular space in most of the cells was too much while in the experimental groups 1, 2, and 3 receiving Omega-3 fish oil supplements and thioacetamide it was minimized. These protective effects were dose dependent. In addition, in the group receiving thioacetamide, blood cells were observed in renal tubules, while this was not the case in the experimental groups 1, 2 and 3 receiving omega-3 fish oil supplement and thioacetamide. In the group receiving thioacetamide, cellular infiltration was observed in some areas of the renal capsule. This was rarely seen in the experimental groups, 1, 2 and 3 which received omega- 3 fish oil supplement and thioacetamide that is because of the dosedependent protective effect (Figure 1C, 1D, 1E, and 1F).

\section{Discussion}

The mean serum potassium concentration in only the experimental group receiving omega-3 fish oil supple- 

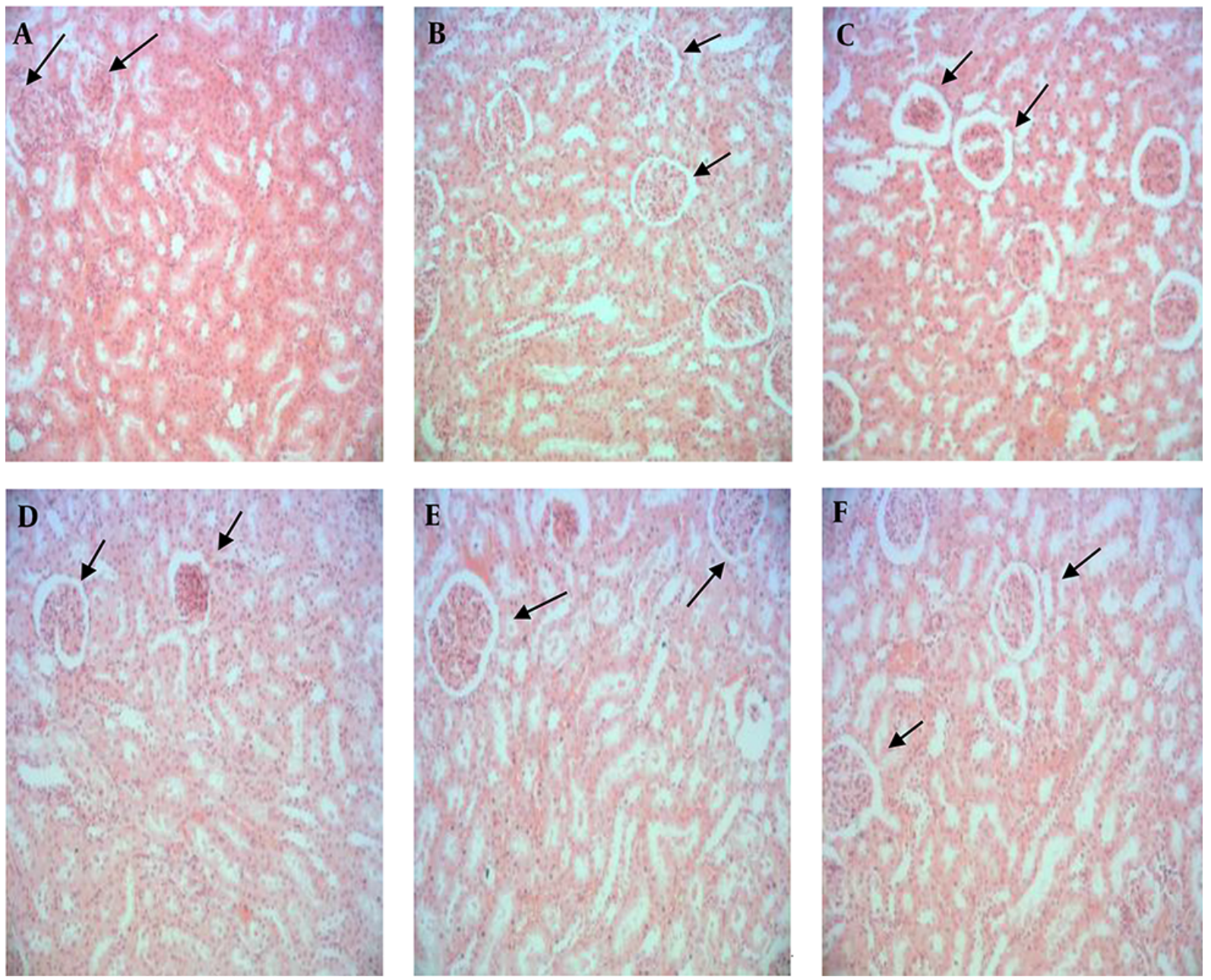

A, control group; B, sham group; C, group receiving thioacetamide; D, E, F, experimental groups receiving omega-3 fish oil supplement at the doses of 100,200 and 300 mg/kg, respectively and thioacetamide.

ment at the dose of $200 \mathrm{mg} / \mathrm{kg}$ significantly reduced compared to the group receiving thioacetamide. The mean serum sodium concentration in all experimental groups receiving omega-3 fish oil supplement and thioacetamide showed a significant decrease compared to the group receiving thioacetamide.This means that the omega-3 fish oil supplement has protective effects on kidney cells against the damage caused by thioacetamide, a fact which was also confirmed in histopathological studies. In general, the results of this study are in line with the results of other researchers [19].

In 2013, Khan and colleagues studied the protective effects of omega-3 unsaturated fatty acids against the oxidative damage and nephric toxicity induced by nitrite in rat kidney. Sodium nitrite changed the activities of urea nitro- gen, serum creatinine .Fish oil diet modified renal parameters. The results showed that fish oil rich in omega-3 might reduce oxidative damage and nephrotoxocity induced by sodium nitrite [20]. In the study conducted by Fassett and colleagues in 2010 it was shown that Omega-3 fatty acids were beneficial in the treatment of kidney diseases. In vivo and in vitro studies supported the effects of omega-3 on inflammatory pathways involved in kidney disease. It has been shown that omega-3 in patients with Immunoglobulin A nephropathy decreases blood pressure and prevents the progression of renal disease [21]. The study done by Ajami et al. in 2013 demonstrated that the exposure to DHA + EPA prevented the cellular death and oxidative stress induced by ischemia reperfusion through reducing creatinine clearance and MDA level [22]. A study conducted by 
An et al. in 2009 showed that omega-3 supplement could reduce the upregulation of profibrotic, proinflammatory and prooxidant routes and modified tubulointersititial fibrosis [23]. In the study done by Takase et al. in 2011 it was indicated that EPA blocked the development of tubulointersititial damage in models with Thy- 1 nephritis and had inhibitory effects on inflammatory molecules by regulating IKBa in cultured renal cells [24]. The study that Abdou et al. conductd in 2014 declared that omega-3 fatty acids prevented renal toxicity induced by lead in rats [25]. Peake et al. in 2011 concluded that consuming fish oils prevented the oxidative stress, fibrosis and inflammation related to kidney damage in rats [26]. In the study done by Hassan and Grant in 2009 showed that oral administration of omega-3 fatty acid can increase survival following renal injury [27].

The results of this study showed that the administration of omega-3 fish oil supplement in rats with thioacetamide-induced lipid dysfunction significantly decreased total cholesterol. The average concentration of serum total cholesterol only in the experimental group receiving $300 \mathrm{mg} / \mathrm{kg}$ omega-3 fish oil showed significant decrease compared to the thioacetamide recipient $(\mathrm{P} \leq$ 0.05). In the study done by Martini et al. (2008) it was found that dietary restriction and supplements containing omega-3 can stop blood cholesterol increase by regulating the activity of HMG COA R through controlling the production of ROS and phosphorization [28]. The study of Wergedahl et al. (2009) indicated that a combination of fish oil (FO) and fish protein hydrolysates could lower plasma cholesterol levels, which was due to their effect in reducing HDL cholesterol; while the concentration of hepatic total cholesterol increased in comparison to the control rats and the rats fed by diets containing FPH or FO alone. The cholesterol-lowering effect of FPH and FO was due to the decrease in the secretion of low density lipoproteins (LDL) from the liver [29]. In a study in 2012, Kim et al. found that omega 3 fatty acids had protective effects against insulin resistance induced by obesity and hepatic steatosis. Omega-3 could also improve hyperlipidimia induced by diet and fatty liver through inducing the expression of cytochrome CYP7A1 and the activation of cholesterol catabolism to bile acid [30]. In their study Al-Gayyar et al. in 2012 concluded that the consumption of fish oil for 6 months could improve lipid profiles in patients with none alcoholic fatty liver disease (NAFLD) [31]. In the study done by Sekhon-Loodu et al. in 2014 it was indicated that apple flavonols and omega-3 polyunsaturated fatty acid-rich fish oil significantly improved blood lipid profiles in rats with diet-induced hyperlipidemia and LPS-induced acute inflammation [32].

The results of this study showed that the mean serum concentration of FBS in all experimental groups receiving omega-3 fish oil and thioacetamide increased compared to the group receiving thioacetamide; however, it was not significant.

The study of Kaushik et al. in 2009 showed that a high intake of long chains of omega-3 fish oil didn't decrease the risk of type 2 diabetes mellitus, on the contrary, the consumption of omega-3 fish oil could lead to an average expansion of the disease [33]. Omega-3 fatty acids may increase the concentration of blood glucose without causing other adverse metabolic conditions. In ob/ob mice the absorption of dietary fish oil could increase insulin sensitivity in adipose and hepatic tissue [34]. In general, in mice fed with fish oil Omega-3, the up-regulation of insulin receptor substrate-2 (IRS-2), insulin receptor substrate-1(IRS-1), Peroxisome proliferator-activated receptor gamma (PPAR \&) genes and GLUT 2, 4 and increase in the production of adiponectin and AMP kinase phosphorylation have been observed [33]. It was also found that PPAR alpha played a key role in modulating the effects of omega-3. In wild rats with PPAR alpha insulin sensitivity could be corrected by fish oil while in mice without PPAR alpha, these supplements would remove the modified hepatic sensitivity, suggesting that EPA, DHA found in fish oil may improve insulin sensitivity in projects related to PPAR alpha. The results showed that omega-3 played a role in glucose homeostasis [34]. In the study conducted by Oh and Walenta in 2014 it was indicated the omega-3 fish oil fatty acid had beneficial effects on obesity and glucose homeostasis whose effects were mostly due to its antiinflammatory properties exerted through affecting its receptor (free fatty acid receptor 4 (FFAR4)) [35]. The study done by Feillet-Coudray et al. in 2013 showed that a diet rich in omega-3 fatty acids stabilized and improved sensitivity to insulin [36]. Bouchard-Mercier et al. in 2014 indicated that a variety of genes, encoding sterol regulatory element binding transcription factor 1 (SREBF1), modified insulin sensitivity in response to fish oil supplementation [37].

In general, the results of this study are in line with the results of other researchers it appears that the oral administration of omega-3 fish oil supplement could exert protective effects on thioacetamide induced lipid and renal toxicity by neutralizing free radicals, stimulating the activity of antioxidant enzymes, and reducing the production of inflammatory cytokines. However, more research is needed in this respect. While studying the sources, no similar study could be found on the protective effects of omega3 fish oil on lipid and renal changes within 3 months, so we were not able to compare our results with them .In future studies it is necessary to compare the renal antioxidant enzymes. Also, the molecular changes in the genes that cause 
cell death should be studied so that it will be more conclusively possible to find the effects of this supplement on hepatic and renal toxicities in rats.

The results show that oral administration of omega3 fish oil supplement has protective effects on thioacetamide induced lipid and renal dysfunction. But people should be careful when taking it long-term because it may cause adverse effects on their kidneys .If further studies confirm these results, it will be advisable to add omega-3 fish oil supplement to the diet of people with Lipid and kidney dysfunction.

\section{Acknowledgments}

Hereby the authors express their deep appreciation for the sincere cooperation devoted to them by the research deputy of Shiraz Azad University to conduct this research. The results described in this paper are part of a PhD thesis No. 16330509931001.

\section{Footnotes}

Authors' Contribution: Davood Moghadamnia contributed in sample collection and were responsible for functional tests. Mokhtar Mokhtari and Saeed Khatamsaz has been involved in study design and experimental investigation.

Conflict of Interest: The authors declare that they have no conflict of interests.

Funding/Support: This study has been funded by Shiraz Islamic Azad University.

\section{References}

1. Ozbek E. Induction of oxidative stress in kidney. Int J Nephrol. 2012;2012:465897. doi: 10.1155/2012/465897. [PubMed: 22577546].

2. Begum Q, Noori S, Mahboob T. Antioxidant effect of sodium selenite on thioacetamide-induced renal toxicity. Pak J Biochem Mol Biol. 2011;44(1):21-6.

3. Plourde M, Cunnane SC. Extremely limited synthesis of long chain polyunsaturates in adults: implications for their dietary essentiality and use as supplements. Appl Physiol Nutr Metab. 2007;32(4):619-34. doi: 10.1139/H07-034. [PubMed:17622276].

4. Ashtiyani SC, Najafi H, Kabirinia K, Vahedi E, Jamebozorky L. Oral omega-3 fatty acid for reduction of kidney dysfunction induced by reperfusion injury in rats. Iran J Kidney Dis. 2012;6(4):275-83. [PubMed: 22797097].

5. Aukema HM, Lu J, Borthwick F, Proctor SD. Dietary fish oil reduces glomerular injury and elevated renal hydroxyeicosatetraenoic acid levels in the JCR:LA-cp rat, a model of the metabolic syndrome. Br J Nutr. 2013;110(1):11-9. doi: 10.1017/S0007114512004606. [PubMed: 23151363].

6. Mezesova L, Jendruchova-Javorkova V, Vlkovicova J, Okruhlicova L, Frimmel K, Navarova J, et al. Supplementation with n-3 polyunsaturated fatty acids to lipopolysaccharide-induced rats improved inflammation and functional properties of renal Na,K-ATPase. Nutr
Res. 2013;33(9):772-9. doi: 10.1016/j.nutres.2013.06.001. [PubMed: 24034577].

7. Gani OA, Sylte I. Molecular recognition of docosahexaenoic acid by peroxisome proliferator-activated receptors and retinoidX receptor alpha. J Mol Graph Model. 2008;27(2):217-24. doi: 10.1016/j.jmgm.2008.04.008. [PubMed: 18547851].

8. Kadir FA, Othman F, Abdulla MA, Hussan F, Hassandarvish P. Effect of Tinospora crispa on thioacetamide-induced liver cirrhosis in rats. Indian J Pharmacol. 2011;43(1):64-8. doi: 10.4103/0253-7613.75673. [PubMed: 21455425].

9. Stankova P, Kucera O, Lotkova H, Rousar T, Endlicher R, Cervinkova Z. The toxic effect of thioacetamide on rat liver in vitro. Toxicol In Vitro. 2010;24(8):2097-103. doi: 10.1016/j.tiv.2010.06.011. [PubMed: 20600801].

10. Chilakapati J, Korrapati MC, Hill RA, Warbritton A, Latendresse JR, Mehendale HM. Toxicokinetics and toxicity of thioacetamide sulfoxide: a metabolite of thioacetamide. Toxicology. 2007;230(2-3):105-16. doi: 10.1016/j.tox.2006.11.050. [PubMed: 17187915].

11. Sirag HM. Biochemical studies on thioacetamide toxicity in male albino rats and the role of tomato juice as an antioxidant. Mansoura J Forensic Med Clin Toxicol. 2007;15:90-114.

12. Goksu Erol AY, Avci G, Sevimli A, Ulutas E, Ozdemir M. The protective effects of omega 3 fatty acids and sesame oil against cyclosporine A-induced nephrotoxicity. Drug Chem Toxicol. 2013;36(2):241-8. doi: 10.3109/01480545.2012.710627. [PubMed: 22950701].

13. Henry RJ. In: Principles and techniques. Henry RJ, editor. Harper \& Ow publishers; 1974. Creatinine measurements with colorimetric method.

14. Patton CJ, Crouch SR. Spectrophotometric and kinetics investigation of the Berthelot reaction for the determination of ammonia. Analyt Chem. 1977;49(3):464-9. doi:10.1021/ac50011a034.

15. Trinder PA. Colorimetric estimation of glucose concentration. Ann Clin Biochem. 1969;6:2.

16. Richmond W. Preparation and properties of a cholesterol oxidase from Nocardia sp. and its application to the enzymatic assay of total cholesterol in serum. Clin Chem. 1973;19(12):1350-6. [PubMed: 4757363].

17. Madani H, Talebolhosseini M, Asgary S, Naderi GH. Hepatoprotective activity of Silybum marianum and Cichorium intybus against thioacetamide in rat. PakJ Nutr. 2008;7(1):172-6.

18. Kadir FA, Kassim NM, Abdulla MA, Yehye WA. Effect of oral administration of ethanolic extract of Vitex negundo on thioacetamide-induced nephrotoxicity in rats. BMC Complement Altern Med. 2013;13:294. doi: 10.1186/1472-6882-13-294. [PubMed: 24499255].

19. El-Mesery M, Al-Gayyar M, Salem H, Darweish M, El-Mowafy A. Chemopreventive and renal protective effects for docosahexaenoic acid (DHA): implications of CRP and lipid peroxides. Cell Div. 2009;4:6. doi: 10.1186/1747-1028-4-6. [PubMed: 19341447].

20. Khan MW, Priyamvada S, Khan SA, Khan S, Naqshbandi A, Yusufi AN. Protective effect of omega-3 polyunsaturated fatty acids (PUFAs) on sodium nitroprusside-induced nephrotoxicity and oxidative damage in rat kidney. Hum Exp Toxicol. 2012;31(10):1035-49. doi: 10.1177/0960327112444475. [PubMed: 22549094].

21. Fassett RG, Gobe GC, Peake JM, Coombes JS. Omega-3 polyunsaturated fatty acids in the treatment of kidney disease. Am J Kidney Dis. 2010;56(4):728-42. doi: 10.1053/j.ajkd.2010.03.009. [PubMed: 20493605].

22. Ajami M, Davoodi SH, Habibey R, Namazi N, Soleimani M, PazokiToroudi H. Effect of DHA+EPA on oxidative stress and apoptosis induced by ischemia-reperfusion in rat kidneys. Fundam Clin Pharmacol. 2013;27(6):593-602. doi:10.1111/j.1472-8206.2012.01066.x. [PubMed: 22943605]. 
23. An WS, Kim HJ, Cho KH, Vaziri ND. Omega-3 fatty acid supplementation attenuates oxidative stress, inflammation, and tubulointerstitial fibrosis in the remnant kidney. Am J Physiol Renal Physiol. 2009;297(4):F895-903. doi:10.1152/ajprenal.00217.2009. [PubMed: 19656915].

24. Takase O, Hishikawa K, Kamiura N, Nakakuki M, Kawano H, Mizuguchi $\mathrm{K}$, et al. Eicosapentaenoic acid regulates IkappaBalpha and prevents tubulointerstitial injury in kidney. Eur J Pharmacol. 2011;669(1-3):12835. doi: 10.1016/j.ejphar.2011.07.043. [PubMed: 21871881].

25. Abdou HM, Hassan MA. Protective role of omega-3 polyunsaturated fatty acid against lead acetate-induced toxicity in liver and kidney of female rats. Biomed Res Int. 2014;2014:435857. doi:10.1155/2014/435857. [PubMed: 25045676].

26. Peake JM, Gobe GC, Fassett RG, Coombes JS. The effects of dietary fish oil on inflammation, fibrosis and oxidative stress associated with obstructive renal injury in rats. Mol Nutr Food Res. 2011;55(3):400-10. doi: 10.1002/mnfr.201000195. [PubMed: 21370451].

27. Hassan IR, Gronert K. Acute changes in dietary omega-3 and omega- 6 polyunsaturated fatty acids have a pronounced impact on survival following ischemic renal injury and formation of renoprotective docosahexaenoic acid-derived protectin D1. J Immunol. 2009;182(5):3223-32. doi: 10.4049/jimmunol.0802064. [PubMed: 19234220].

28. Martini C, Pallottini V, De Marinis E, Marino M, Cavallini G, Donati A, et al. Omega-3 as well as caloric restriction prevent the age-related modifications of cholesterol metabolism. Mech Ageing Dev. 2008;129(12):722-7. doi: 10.1016/j.mad.2008.09.010. [PubMed: 18930075].

29. Wergedahl H, Gudbrandsen OA, Rost TH, Berge RK. Combination of fish oil and fish protein hydrolysate reduces the plasma cholesterol level with a concurrent increase in hepatic cholesterol level in high-fat-fed Wistar rats. Nutrition. 2009;25(1):98-104. doi: 10.1016/j.nut.2008.07.005. [PubMed:18752928].

30. Kim EH, Bae JS, Hahm KB, Cha JY. Endogenously synthesized n3 polyunsaturated fatty acids in fat-1 mice ameliorate high-fat diet-induced non-alcoholic fatty liver disease. Biochem Pharmacol. 2012;84(10):1359-65. doi: 10.1016/j.bcp.2012.08.029. [PubMed: 22981383].

31. Al-Gayyar MM, Shams ME, Barakat EA. Fish oil improves lipid metabolism and ameliorates inflammation in patients with metabolic syndrome: impact of nonalcoholic fatty liver disease. Pharm Biol. 2012;50(3):297-303. doi: 10.3109/13880209.2011.604088. [PubMed: 22103753].

32. Sekhon-Loodu S, Catalli A, Kulka M, Wang Y, Shahidi F, Rupasinghe HP. Apple flavonols and n-3 polyunsaturated fatty acid-rich fish oil lowers blood C-reactive protein in rats with hypercholesterolemia and acute inflammation. Nutr Res. 2014;34(6):535-43. doi 10.1016/j.nutres.2014.05.002. [PubMed: 25026921].

33. Kaushik M, Mozaffarian D, Spiegelman D, Manson JE, Willett WC Hu FB. Long-chain omega-3 fatty acids, fish intake, and the risk of type 2 diabetes mellitus. Am J Clin Nutr. 2009;90(3):613-20. doi: 10.3945/ajcn.2008.27424. [PubMed:19625683].

34. Gonzalez-Periz A, Horrillo R, Ferre N, Gronert K, Dong B, MoranSalvador E, et al. Obesity-induced insulin resistance and hepatic steatosis are alleviated by omega-3 fatty acids: a role for resolvins and protectins. FASEB J. 2009;23(6):1946-57. doi: 10.1096/fj.08-125674. [PubMed: 19211925].

35. Oh DY, Walenta E. Omega-3 Fatty Acids and FFAR4. Front Endocrinol (Lausanne). 2014;5:115. doi: 10.3389/fendo.2014.00115. [PubMed: 25076939].

36. Feillet-Coudray C, Aoun M, Fouret G, Bonafos B, Ramos J, Casas $\mathrm{F}$, et al. Effects of long-term administration of saturated and n3 fatty acid-rich diets on lipid utilisation and oxidative stress in rat liver and muscle tissues. Br J Nutr. 2013;110(10):1789-802. doi: 10.1017/S0007114513001311. [PubMed: 23656726].

37. Bouchard-Mercier A, Rudkowska I, Lemieux S, Couture P, Perusse L Vohl MC. SREBF1 gene variations modulate insulin sensitivity in response to a fish oil supplementation. Lipids Health Dis. 2014;13:152. doi 10.1186/1476-511X-13-152. [PubMed: 25270430]. 